\title{
Therapies for acute myeloid leukemia: vosaroxin
}

\author{
Hamid Sayar' \\ Parvaneh Bashardoust ${ }^{2}$ \\ 'Indiana University Simon Cancer \\ Center, Department of Medicine, \\ Indiana University School of Medicine, \\ Indianapolis, IN, USA; ${ }^{2}$ Oceania \\ University of Medicine, OUM-North \\ America, Indianapolis, IN, USA
}

This article was published in the following Dove Press journal:

OncoTargets and Therapy

7 August 2017

Number of times this article has been viewed
Abstract: Vosaroxin, a quinolone-derivative chemotherapeutic agent, was considered a promising drug for the treatment of acute myeloid leukemia (AML). Early-stage clinical trials with this agent led to a large randomized double-blind placebo-controlled study of vosaroxin in combination with intermediate-dose cytarabine for the treatment of relapsed or refractory AML. The study demonstrated better complete remission rates with vosaroxin, but there was no statistically significant overall survival benefit in the whole cohort. A subset analysis censoring patients who had undergone allogeneic stem cell transplantation, however, revealed a modest but statistically significant improvement in overall survival particularly among older patients. This article reviews the data available on vosaroxin including clinical trials in AML and offers an analysis of findings of these studies as well as the current status of vosaroxin.

Keywords: AML, acute myeloid leukemia, vosaroxin, SNS-595, cytarabine

\section{Introduction}

Acute myeloid leukemia (AML) comprises a heterogeneous group of hematologic malignancies characterized by expansion of clonal myeloid blasts in the bone marrow, blood, and other tissues. The American Cancer Society estimates the diagnosis of 21,380 new AML cases and about 10,590 deaths from this disease in 2017. ${ }^{1}$ The incidence of AML increases with age, with median age of 67 years at diagnosis. ${ }^{1}$ Moreover, age is a major prognostic factor in AML, with more dismal outcome in older individuals. Patients at the ages of 60-69, 70-79, and 80 years and older demonstrate 5 -year survival of $13 \%, 3 \%$, and $0 \%$, respectively. ${ }^{2}$

Unfortunately, despite intense research, little has changed in the effective treatment of AML over the past 3 decades. Induction chemotherapy with anthracyclines and cytarabine remains the standard approach for the first-line treatment of this disease. Many older patients are unable to tolerate such therapy and therefore considered ineligible for chemotherapeutic induction. Among those who receive induction chemotherapy, great majority will either not achieve a remission or experience relapse later. In addition, potential cardiotoxicity of anthracyclines has always been a concern, particularly in older population with higher incidence of underlying cardiovascular pathology. Hypomethylating agents, decitabine and azacitidine, have gained popularity for the treatment of older adults with AML due to their outpatient administration and assumed better tolerability. These agents, however, have not demonstrated superior long-term outcome compared with other approaches. ${ }^{3}$

Patients with relapsed or refractory AML, particularly older ones, suffer from an extremely unfavorable outcome with limited therapeutic options, small chance of achievement of a complete remission (CR), and short median overall survival (OS). ${ }^{4}$ Cytarabine monotherapy or cytarabine-containing combination regimens are usually administered as salvage therapy in those considered candidates for intense therapy,
Correspondence: Hamid Saya Indiana University Simon Cancer Center, Indiana University School of Medicine. Indiana Cancer Pavilion, 535 Barnhill Drive, Room 473, Indianapolis, IN 46202, USA

Tel + I 3179483855

Fax +I 3179443684

Email ssayar@iu.edu (c) (1) (5) 2017 Sayar and Bashardoust. This work is published and licensed by Dove Medical Press Limited. The full terms of this license are available at https://www.dovepress.com/terms.php cC) and incorporate the Creative Commons Attribution - Non Commercial (unported, v3.0) License (http://creativecommons.org/licenses/by-nc/3.0/). By accessing the work you hereby accept the Terms. Non-commercial uses of the work are permitted without any further permission from Dove Medical Press Limited, provided the work is properly attributed. For permission for commercial use of this work, please see paragraphs 4.2 and 5 of our Terms (https://www.dovepress.com/terms.php). 
offering low CR rates, short remission duration, and high toxicity. A recent international study treating patients with relapsed or refractory AML with several regimens reported only about $20 \%$ CR rate. ${ }^{5}$

Several clinical trials have studied different agents for the treatment of older patients with AML, but none has shown a definitive improvement in outcome. Vosaroxin, a chemotherapeutic agent, has demonstrated some promising results in this patient population but was not able to gain approval from the US Food and Drug Administration (FDA) for clinical use. This article reviews the available clinical data on the treatment of AML with this agent.

\section{Structure and function of vosaroxin}

Vosaroxin (formerly SNS-595) is an anticancer quinolonederivative chemotherapeutic agent with a naphthyridine core similar to quinolone antibiotics. ${ }^{6}$ Vosaroxin does not have antibacterial activity, but demonstrates cytotoxicity in the cancer cell lines. ${ }^{7}$ This cytotoxicity is exerted through two major mechanisms, inhibition of type II topoisomerase and intercalation into the DNA. ${ }^{8}$ Type II topoisomerases are essential for the cell survival. These enzymes maintain normal DNA topology and chromosome condensation by constant disentangling of knotted over-wound DNA that is formed during replication process. ${ }^{9}$ Poisoning of type II topoisomerase would be catastrophic to actively replicating cells, resulting in cell death. Anthracyclines are chemotherapeutic agents known for their topoisomerase II poisoning activity. There are two limitations; however, to the clinical applicability of these agents, they 1) are subject to the P-glycoprotein receptor-mediated efflux pump that actively throws them out of the cell, 2) can cause myocardial cell injury resulting in cardiotoxicity mainly due to the induction of intracellular reactive oxygen species (ROS). ${ }^{10,11}$ When tested in cell lines, vosaroxin activity was not subject to P-glycoprotein pump. ${ }^{7}$ In addition, cell-based studies have demonstrated that vosaroxin does not generate significant ROS, therefore is less likely to cause dose-dependent cardiotoxicity. ${ }^{6}$ Vosaroxin intercalates into DNA at specific G/C-rich sites. ${ }^{8}$ Incorporation of vosaroxin into DNA also induces DNA damage, G2-phase cell cycle arrest, and S-phase prolongation which will lead to cell apoptosis. ${ }^{6,8,9}$ The property of vosaroxin inducing DNA damage at specific $\mathrm{G} / \mathrm{C}$-rich regions might translate into a less mutagenic effect on normal cells compared with anthracyclines which exhibit a nonspecific DNA intercalation. ${ }^{6}$

Vosaroxin has shown favorable pharmacokinetic properties in rat and monkey, and it is believed to be less cardiotoxic than anthracyclines in human beings. ${ }^{12}$ In addition, vosaroxininduced apoptosis is p53 independent; therefore, it may evade p53-dependent drug resistance. ${ }^{7}$ Finally, since vosaroxin is minimally metabolized by enzymatic processes, it may be less subject to interaction with other drugs. ${ }^{13}$

\section{Preclinical data}

Vosaroxin has demonstrated cytotoxic activity in tumor models. A tumor growth inhibition of $63 \%-88 \%$ was observed in murine syngeneic tumor models of Lewis lung carcinoma, M5076 ovarian sarcoma, and colon 26 and xenograft models of ovarian, breast, colon, gastric, and melanoma lung cancers, as well as two hematologic malignancies. ${ }^{7}$ Vosaroxin combined with cytarabine demonstrated additive or synergistic activity on acute leukemia cell lines HL-60 (acute promyelocytic leukemia) and MV4-11 (AML). ${ }^{14}$ A suggested explanation for the enhanced activity of this combination is that vosaroxin exerts its effect after the cytarabine-induced DNA damage that makes vulnerable cells exit the S-phase and enter the G2-phase. ${ }^{14}$

\section{Phase I study}

A Phase Ib dose-escalation study evaluated pharmacokinetics and safety of vosaroxin and established the maximum tolerated dose (MTD) and dose-limiting toxicities (DLTs) in patients with relapsed or refractory leukemia. ${ }^{15}$ Approximately $85 \%$ of patients had AML, $78 \%$ with refractory disease. Vosaroxin dose was escalated in both a weekly schedule for 3 weeks (days 1, 8, 15) and a twice-weekly schedule for 2 weeks (days 1, 4, 8, 11). A total of 73 patients (median age 65 years) were treated. In the weekly schedule, 42 patients received vosaroxin $18-90 \mathrm{mg} / \mathrm{m}^{2}$ and the MTD was $72 \mathrm{mg} / \mathrm{m}^{2}$. In the twice-weekly schedule, 31 patients received vosaroxin $9-50 \mathrm{mg} / \mathrm{m}^{2}$ and the MTD was determined at $40 \mathrm{mg} / \mathrm{m}^{2}$. The DLT was stomatitis. Primary nonhematologic toxicities were gastrointestinal symptoms and neutropenic fever. Other frequent non-hematologic toxicities that occurred in $>30 \%$ of patients, but were not dose limiting, included fatigue, anorexia, peripheral edema, and dyspnea. Vosaroxin demonstrated linear pharmacokinetic properties over the dose range of $9-90 \mathrm{mg} / \mathrm{m}^{2}$ when administered once or twice weekly. The average terminal half-life of the drug was about 25 hours, and the clearance was non-renal. No induction or inhibition of vosaroxin metabolism was observed. Evidence of DNA damage was confirmed through the detection of elevated intracellular $\gamma \mathrm{H} 2 \mathrm{AX}$, a product of histone phosphorylation in response to DNA breaks. Five patients (7\%) achieved a CR or CR with incomplete platelet 
recovery (CRp), of whom four were on weekly and one on the twice-weekly treatment schedule.

\section{Phase II studies in AML \\ REVEAL-I: single-agent vosaroxin in older population}

This Phase II trial evaluated vosaroxin in patients aged 60 years or older with previously untreated AML. ${ }^{16}$ Eligibility criteria required at least one of the following: age 70 years or older, intermediate or unfavorable cytogenetics, or an antecedent hematologic disorder. The weekly regimen was opted for, and a dose optimization was pursued through sequential cohorts (A: $72 \mathrm{mg} / \mathrm{m}^{2}$, days 1, 8, 15; B: $72 \mathrm{mg} / \mathrm{m}^{2}$, days 1, 8; C: $72 \mathrm{mg} / \mathrm{m}^{2}$ [C72] or $90 \mathrm{mg} / \mathrm{m}^{2}$ [C90], days 1, 4). A total of 113 patients received at least one induction therapy, among them $26(23 \%)$ required a second induction due to residual disease on the day 14 marrow. Grade 3/4 hematologic toxicities including neutropenic fever were frequent $(50 \%)$. Grade 3/4 infections had higher incidence with schedule A (76\%) than with the other three schedules (B: $57 \%$; C72: 48\%; C90: 55\%). Grade $\geq 3$ (bacterial, fungal, or viral) sepsis occurred in $39 \%$ of patients, with lowest frequency in the schedule C72 cohort. The most frequent non-hematologic toxicities included gastrointestinal (diarrhea 74\%, nausea $70 \%$, stomatitis 60\%) and metabolic effects (hypokalemia $62 \%$, anorexia $59 \%$, hypomagnesemia $43 \%$ ). The incidences of diarrhea, stomatitis, hypokalemia, and anorexia were lower with schedules $B$ and $C$ than with schedule A. A total of 91 patients $(81 \%)$ had $\geq 1$ serious adverse event (SAE). The most common SAEs included pneumonia (24\%), neutropenic fever (21\%), and stomatitis (10\%). Of 113 patients, 103 died over the study period. A total of 80 deaths (78\%) were due to progressive disease. All-cause mortality rates were $12 \%$ and $31 \%$ within first 30 and 60 days, respectively. Lowest mortality rate was seen in schedule C 72 : 7\% and 17\% 30- and 60-day mortality, respectively.

CR/CRp was achieved in 36 patients (32\%), with 33 CRs (29\%). The highest CR/CRp rates occurred with schedules A (41\%) and C72 (35\%). Most remissions (28 of 36, 78\%) occurred with one induction therapy. A total of 26 patients received a second induction course, of whom eight (31\%) obtained a $\mathrm{CR} / \mathrm{CRp}$. The median OS for all patients was 7 months (95\% CI, 4.0-9.2 months) with 8.6 and 7.7 months for schedules A and C72, respectively. A 1-year survival rate of $38 \%$ was reported with both schedules A and C72. The median OS of the 36 responders (CR and CRp) was 15.5 months (95\% CI, 12.7-18.3 months), with a median leukemia-free survival (LFS) of 6.5 months (95\% CI, 4.9-9.8 months).
Schedule C72 exhibited the most favorable safety and efficacy, with faster hematologic recovery (median 27 days) and lowest incidence of aggregate sepsis (24\%) and 30- and 60 -day all-cause mortality (7\% and 17\%, respectively). For this group, CR was $31 \%$, CR/CRp was $35 \%$, median OS was 7.7 months, and 1-year OS was 38\%.

\section{Combination of vosaroxin and cytarabine in relapsed/refractory $A M L$}

A combination of vosaroxin and cytarabine was assessed in a Phase Ib/II study in patients with relapsed or refractory AML. ${ }^{17}$ Escalating doses of vosaroxin (10-minute infusion; $10-90 \mathrm{mg} / \mathrm{m}^{2}$; days 1,4$)$ were given with cytarabine on one of two schedules: schedule A (24-hour continuous intravenous [IV] infusion; $400 \mathrm{mg} / \mathrm{m}^{2} /$ day; days 1-5) or schedule B (2-hour IV infusion; $1 \mathrm{~g} / \mathrm{m}^{2} /$ day; days $\left.1-5\right)$. A total of 56 patients on schedule A and 52 on schedule B received at least one dose of vosaroxin and/or cytarabine. In schedule A, the MTD of vosaroxin was $80 \mathrm{mg} / \mathrm{m}^{2}$ (DLTs: grade 3 stomatitis and bowel obstruction lasting more than 7 days). The MTD was not reached for schedule $B$. The highest vosaroxin dose tested on schedule B was $90 \mathrm{mg} / \mathrm{m}^{2}$, which was selected for Phase III study. The most common non-hematologic toxicities were diarrhea (76\%), hypokalemia (73\%), nausea (67\%), and stomatitis (66\%). Among the 108 treated patients across both schedules, 24 (22\%) achieved a CR, and the combined CR and CRp was observed in 28 patients $(26 \%)$. The 30 - and 60-day all-cause mortality rates were $2.5 \%(2 / 78)$ and $9.0 \%$ (7/78), respectively, among patients treated at MTD or recommended Phase II dose. Mortality rate was $2 \%$ in 30 days and $8 \%$ in 60 days for all patients on schedule B.

\section{Phase III VALOR study}

Findings of previous trials led to the design of a Phase III randomized double-blind trial named VALOR (Vosaroxin and Ara-C combination EvaLuating Overall Survival in Relapsed/Refractory AML). ${ }^{18}$ Patients were randomized 1:1 to receive cytarabine ( $1 \mathrm{~g} / \mathrm{m}^{2} /$ day IV for 5 days) plus either vosaroxin ( $90 \mathrm{mg} / \mathrm{m}^{2} \mathrm{IV}$ first cycle; $70 \mathrm{mg} / \mathrm{m}^{2}$ subsequently) or placebo on days 1 and 4. Patients older than 18 with AML in first relapse or with refractory disease were eligible. Relapsed disease was defined as recurrence between 90 days and 24 months after first remission. Persistent disease at least 28 days following the initiation of induction therapy and relapse within 90 days of first remission were considered refractory disease. All patients should have received anthracycline- and cytarabine-containing induction therapy previously, and a maximum of two previous induction 
therapies were allowed. All molecular and cytogenetic subtypes were eligible. Patients with left ventricular ejection fraction of less than $40 \%$ and those who had received cytarabine at a total dose of $5 \mathrm{~g} / \mathrm{m}^{2}$ or more within 90 days of randomization were ineligible.

A total of 711 patients were enrolled and randomized; of whom, 705 received treatment (355 vosaroxin and 350 placebo). All 711 patients were included in the efficacy analysis, while the safety analysis was conducted on the 750 treated patients. A total of 148 patients (21\%) required a second induction therapy due to residual AML in the day 14 marrow $(70[20 \%]$ in the vosaroxin arm and 78 [22\%] in the placebo arm). A total of 97 patients (27\%) in the vosaroxin group and $50(14 \%)$ in the placebo group received at least one consolidation cycle, while up to two consolidations were allowed. A total of 210 (30\%) patients underwent allogeneic stem cell transplantation. The number of transplanted patients was similar between the two arms, $107(30 \%)$ and $103(29 \%)$ in the vosaroxin and placebo groups, respectively. However, as expected, a considerably higher number of patients younger than 60 years received transplantation as opposed to those aged 60 years or older ( $46 \%$ vs $20 \%$ ).

SAEs including neutropenic fever, infection, and gastrointestinal mucosal toxicity were more common in the vosaroxin arm (33\%) than in the placebo arm (17\%). Rate of cardiac toxicities was same in both arms, including atrial fibrillation at $6 \%$ and $7 \%$ in the placebo and vosaroxin arms, respectively, and one myocardial infarction in the vosaroxin arm. Short-term all-cause mortality rates were similar with $8 \%$ vs $7 \% 30$-day mortality and $20 \%$ vs $19 \% 60$-day mortality in the vosaroxin vs placebo groups, respectively.

$\mathrm{CR}$ and $\mathrm{CRp}$ were achieved in $38 \%$ and $19 \%$ of patients on the vosaroxin and placebo arms, respectively. The difference in remission rate was more pronounced in the older age group of 60 years and above. Among patients who achieved a CR, the median LFS was 11.0 months in the vosaroxin group vs 8.7 months in the placebo group $(P=0.63)$.

The median OS was not statistically different between the two groups (7.5 months in the vosaroxin group and 6.1 months in the placebo group; $P=0.061$ ). A predefined analysis, however, that censored patients who had received allogeneic stem cell transplantation, demonstrated a 1.4-month longer OS in the vosaroxin group (median 6.7 vs 5.3 months; $P=0.027$ ). The difference in OS was greatest in patients aged 60 years or older (7.1 vs 5.0 months; $P=0.003$ ) and in those with early relapse ( 6.7 vs 5.2 months; $P=0.039$ ). The OS was not significantly different between the treatment arms in younger patients, refractory cases, or those with late relapse.

\section{Discussion}

Minimal improvement has been made over the past few decades in the treatment of relapsed or refractory AML. While most salvage regimens incorporate a potentially cardiotoxic anthracycline or anthracenedione, vosaroxin, a chemotherapeutic agent with possibly less cardiotoxic effect, represents a promising outlook. The drug underwent standard experimental steps, including Phase I, II, and III studies, for the treatment of patients with relapsed or refractory AML. Table 1 summarizes the clinical trials with this agent and their outcome. Vosaroxin, either as single agent or in combination with cytarabine, was found tolerable within acceptable safety profile even in older patients. Based on early-phase studies, vosaroxin was deemed worthy of moving forward to a large randomized Phase III trial.

The VALOR trial was a large multi-institutional study that followed all necessary rules of a double-blind randomized clinical trial. One critique to the design of this study would be selection of the comparison arm, ie, a cytarabine dose of $1 \mathrm{~g} / \mathrm{m}^{2} /$ day for 5 days. Intermediate-dose cytarabine is commonly used in combination with other agents in salvage regimens such as mitoxantrone, etoposide, and cytarabine (MEC) or fludarabine, cytarabine, granulocyte colony stimulating factor, and iradubicin (FLAG-Ida). However, with a total dosing of $5 \mathrm{mg} / \mathrm{m}^{2}$, single-agent cytarabine may have represented a suboptimal induction attempt.

Remission rates were superior in the vosaroxin/cytarabine arm compared with single-agent cytarabine. However, it remains unclear if vosaroxin/cytarabine could stand noninferior to higher total doses of cytarabine or commonly used combination regimens such as MEC or FLAG-Ida. An argument in support of vosaroxin would be possible better tolerability of vosaroxin/cytarabine than other regimens, at least in the older population.

The higher remission rate with vosaroxin/cytarabine, however, did not translate into a better long-term outcome. Despite the potentially suboptimal comparison arm, VALOR study failed to demonstrate statistically significant prolongation of OS in favor of vosaroxin. Subsequent analysis of data, censoring patients who had undergone allogeneic stem cell transplantation, revealed a modest improvement in OS of 1.4 months with vosaroxin that reached statistical significance. Such finding may reflect lack of long-term efficacy of transplant in this patient population regardless of salvage regimen used for induction. It may also be interpreted as possible higher efficacy of vosaroxin in older population, since the number of transplanted patients was significantly greater among those below the age of 60 years. Indeed, the difference in OS in favor of vosaroxin reached statistical significance 
Table I Clinical studies using vosaroxin

\begin{tabular}{|c|c|c|c|c|}
\hline Study & $\begin{array}{l}\text { Patient } \\
\text { no/disease }\end{array}$ & Treatment & Toxicity & Outcome \\
\hline Phase $\mathrm{Ib}^{15}$ & $\begin{array}{l}73 \\
\operatorname{Re} / \operatorname{Re}\end{array}$ & $\begin{array}{l}\text { A: } \vee \text { weekly } \times 3 \\
\text { B: } \bigvee \text { twice weekly } \times 2\end{array}$ & $\begin{array}{l}\text { Neutropenic fever } \\
\text { Stomatitis } \\
\text { GI }\end{array}$ & $\begin{array}{l}\text { MTD group A: } 90 \mathrm{mg} / \mathrm{m}^{2} \\
\text { MTD group B: } 40 \mathrm{mg} / \mathrm{m}^{2} \\
\text { CR/CRp } 7 \%\end{array}$ \\
\hline Phase ${ }^{1 / 6}$ (REVEAL-I) & $\begin{array}{l}113 \\
\text { Untreated }\end{array}$ & $\begin{array}{l}\text { A: } \vee 72 \mathrm{mg} / \mathrm{m}^{2} \text { weekly } \times 2 \\
\text { B: } \vee 73 \mathrm{mg} / \mathrm{m}^{2} \text { weekly } \times 3 \\
\text { C: } \vee 72 \mathrm{mg} / \mathrm{m}^{2}, \text { d I, } 4 \\
\text { D: } \vee 90 \mathrm{mg} / \mathrm{m}^{2}, \text { d I, } 4\end{array}$ & $\begin{array}{l}\text { Neutropenic fever } \\
\text { Stomatitis } \\
\text { GI (nausea, diarrhea) }\end{array}$ & $\begin{array}{l}\text { CR/CRp } 32 \% \\
\text { MOS of responders } 15.5 \text { mo } \\
30-/ 60 \text {-day all-cause mortality } 12 / 31 \%\end{array}$ \\
\hline $\begin{array}{l}\text { Phase } \mathrm{lb} / \mathrm{II}^{17} \\
\text { (combination) }\end{array}$ & $\begin{array}{l}108 \\
\operatorname{Re} / \operatorname{Re}\end{array}$ & $\begin{array}{l}\text { A: V I0-90 mg/m², d I, } 4 \\
+ \text { Cy } 400 \mathrm{mg} / \mathrm{m}^{2} / \mathrm{d} \text { CIV, d I-5 } \\
\text { B: V I0-90 mg/m², d I, } 4 \\
+ \text { Cy I g/m²/d, d I-5 }\end{array}$ & $\begin{array}{l}\text { Stomatitis } \\
\text { Nausea } \\
\text { Diarrhea }\end{array}$ & $\begin{array}{l}\text { MTD group A: } 80 \mathrm{mg} / \mathrm{m}^{2} \\
\text { MTD group B: not achieved } \\
\text { CR/CRp } 26 \% \\
\text { MOS } 6.9 \text { mo } \\
30-/ 60 \text {-day all-cause mortality } 2.5 / 9 \%\end{array}$ \\
\hline Randomized $^{20}$ & $\begin{array}{l}104 \\
\text { Untreated }\end{array}$ & $\begin{array}{l}\vee 72 \mathrm{mg} / \mathrm{m}^{2}, \mathrm{~d} \mathrm{I}, 4 \\
\text { vs } \\
\text { LDAC } 20 \mathrm{mg} \text { BID, d I-I0 }\end{array}$ & $\begin{array}{l}\mathrm{GI} \text { (stomatitis/diarrhea) } \\
\text { significantly worse in the } V \text { arm }\end{array}$ & $\begin{array}{l}\text { CR/CRp } V \text { vs } L D A C \\
26 \% \text { vs } 30 \% ; P=0.7 \\
12 \text {-mo survival } \vee \text { vs LDAC } \\
12 \% \text { vs } 31 \% ; P=0.003\end{array}$ \\
\hline Randomized $^{20}$ & $\begin{array}{l}104 \\
\text { Untreated }\end{array}$ & $\begin{array}{l}\vee 72 \mathrm{mg} / \mathrm{m}^{2}, \mathrm{~d} \mathrm{I}, 4+\text { LDAC } \\
20 \mathrm{mg} \mathrm{BID}, \mathrm{d} \mathrm{I}-10 \\
\text { vs } \\
\text { LDAC } 20 \mathrm{mg} \text { BID, d I-10 }\end{array}$ & $\begin{array}{l}\text { Gl (stomatitis/diarrhea) } \\
\text { significantly worse in the } V+ \\
\text { LDAC arm }\end{array}$ & $\begin{array}{l}C R / C R P V+L D A C \text { vs } L D A C \\
38 \% \text { vs } 34 \% ; P=0.6 \\
\text { I } 2 \text {-mo survival } V+\text { LDAC vs } L D A C \\
33 \% \text { vs } 37 \% ; P=0.3\end{array}$ \\
\hline $\begin{array}{l}\text { Phase III' } \\
\text { Double-blind, } \\
\text { randomized (VALOR) }\end{array}$ & $\begin{array}{l}705 \\
\operatorname{Re} / \operatorname{Re}\end{array}$ & $\begin{array}{l}\text { V } 90 \mathrm{mg} / \mathrm{m}^{2}, \mathrm{~d} \mathrm{I}, 4 \\
+ \text { Cy I g/m²/d; d I-5 } \\
\text { vs } \\
\text { placebo } \\
+ \text { Cy I g/m²/d; I }-5\end{array}$ & $\begin{array}{l}\text { Neutropenic fever, infection, GI: } \\
\text { V + Cy } 33 \% \\
\text { Placebo + Cy I7\% }\end{array}$ & $\begin{array}{l}\text { CR/CRp } V+\text { Cy vs placebo }+C y \\
38 \% \text { vs } 19 \% \\
\text { MOS V + Cy vs placebo + Cy } \\
\text { All patients: } \\
7.5 \text { vs } 6.1 \text { mo; } P=0.06 \\
\text { Censored for allotransplant: } \\
6.7 \text { vs } 5.3 \text { mo; } P=0.027 \\
\text { Patients aged } 60 \text { years and older: } \\
7.1 \text { vs } 5.0 \text { mo; } P=0.003 \\
\text { Early relapsed patients: } \\
6.7 \text { vs } 5.2 \text { mo; } P=0.039 \\
30 \text {-day all-cause mortality } \\
V+C y \text { vs placebo }+C y 8 \% \text { vs } 7 \% \\
60 \text {-day all-cause mortality } \\
\text { V + Cy vs placebo + Cy } 20 \% \text { vs } 19 \%\end{array}$ \\
\hline
\end{tabular}

Abbreviations: BID, twice daily; CIV, continues intravenous infusion; CR, complete remission; CRp, CR with incomplete platelet recovery; Cy, cytarabine; d, day; GI, gastrointestinal; LDAC, low-dose Ara-C; mo, months; MOS, median overall survival; MTD, maximum tolerated dose; Re/Re, relapsed/refractory; V, vosaroxin.

among patients older than 60 years $(7.1$ vs 5.0 months in the vosaroxin/cytarabine vs cytarabine arms, respectively; $P=0.0030$ ). In addition, a post hoc analysis revealed an OS benefit in patients with unfavorable-risk cytogenetics and FLT3 mutations which collectively comprise the most poorrisk subtypes of AML.

Cardiotoxicity, particularly in older individuals, remains a major concern with the use of anthracyclines. Myocardial cell injury by ROS is believed to be one of the major mechanisms of anthracycline-induced cardiotoxicity. ${ }^{11}$ Although there exists a wide interindividual variability, studies have shown that the risk of cardiomyopathy increases dramatically from less than $0.3 \%$ up to $7 \%$ once the cumulative anthracycline dose exceeds $500-550 \mathrm{mg} / \mathrm{m}^{2}$ of doxorubicin or equivalent. ${ }^{19}$ Considering the fact that cumulative dose of anthracyclines usually remains below this cutoff level after a typical induction chemotherapy at initial diagnosis and one re-induction therapy for relapsed/refractory disease, indeed the incidence of anthracycline-induced cardiomyopathy in real practice remains minimal. Moreover, cardiomyopathy is usually a long-term complication of anthracyclines, occurring after months or years of exposure, while great majority of older AML patients never enjoy a survival long enough to experience such delayed toxicity. In practice, therefore, the traditionally feared anthracycline-induced cardiomyopathy is seen very uncommonly in adults with AML, who mostly belong to an older age group. Nevertheless, since vosaroxin exposure induces generation of less significant amount of 
ROS, it is expected to cause less myocardial cell injury than anthracyclines. As an inclusion criterion, patients enrolled in VALOR study were required to have adequate baseline cardiac function, defined as left ventricular ejection fraction of $40 \%$ or greater. ${ }^{18}$ With a median follow-up of 24.4 months, VALOR study did not report cardiomyopathy among patients who had received vosaroxin. It is unclear from the report whether or not, and how, these patients were monitored for possible delayed cardiac toxicity. Nevertheless, vosaroxin appears to have less potential for cardiotoxicity than anthracyclines, and thus portrays a more attractive agent.

Two randomized trials in previously untreated AML conducted in the UK reported significant gastrointestinal toxicities with vosaroxin at a dose of $72 \mathrm{mg} / \mathrm{m}^{2} .{ }^{20}$ In neither of these studies, the vosaroxin arm demonstrated a superior outcome, and the authors concluded that the lack of benefit was mostly due to increased early mortality associated with this agent. It is to be noted, however, that both studies enrolled patients who were not considered suitable for intensive therapy. These patients therefore would have been at higher risk of complications or mortality with myelosuppressive chemotherapy. In the abovementioned Phase Ib/II study of vosaroxin/cytarabine, the MTD was reached in schedule A at vosaroxin dose of $80 \mathrm{mg} / \mathrm{m}^{2} .{ }^{16}$ Collectively, these findings signal for potential clinically significant toxicity with vosaroxin at doses of $72 \mathrm{mg} / \mathrm{m}^{2}$ and above. In VALOR study, response rates, including CR and CRp, were significantly higher in the vosaroxin/cytarabine group, and also there was higher early mortality attributed to adverse events in this group. We can conclude that the long-term OS benefit of vosaroxin may have been more prominent if vosaroxin-related toxicities could have been reduced or better controlled so a reduction in early mortality achieved. Thus, for future consideration of AML treatment with this drug, a cautious dose modification to avoid significant toxicities while preserving efficacy seems essential. Preparation for more vigorous supportive care would also be important to reduce toxicity-related morbidity and mortality. It is to be noted that the $90 \mathrm{mg} / \mathrm{m}^{2}$ dose of vosaroxin in the VALOR study was chosen based on highest dose used in previous Phase II trial of vosaroxin/cytarabine combination, and not necessarily for a proven higher efficacy. Hence, one may speculate that lower doses, perhaps below $72 \mathrm{mg} / \mathrm{m}^{2}$, may be as efficacious but less toxic.

In conclusion, multiple studies have shown the efficacy of vosaroxin, particularly in combination with intermediatedose cytarabine, in the treatment of AML. In a large randomized study, however, the drug did not demonstrate OS benefit, possibly due to severe toxicities resulting in increased early mortality. A more cautious use of the drug with consideration of appropriate dose modification may overcome unacceptable toxicity while keeping the desirable efficacy. It appears, at least in the relapsed/refractory setting, that the drug may be more promising in the age group of 60 years and older in early relapse, and those with unfavorable-risk cytogenetics or FLT3 mutations. Indeed, the most unmet need in the treatment of AML is focused on these exact patient populations. Appropriate patient selection and cautious dosing may be key for success in future applications of this drug. In addition, further clinical trials with vosaroxin in other settings such as previously untreated AML would be reasonable. Currently, vosaroxin is not approved in the USA by FDA for clinical use in AML. Vosaroxin in combination with infusional cytarabine or hypomethylating agents is in clinical trials for the treatment of AML and high-risk myelodysplastic syndromes.

\section{Disclosure}

Hamid Sayar participated in advisory board for Sunesis Pharmaceuticals and received funding to support clinical trial using vosaroxin. Parvaneh Bashardoust reports no conflicts of interest in this work.

\section{References}

1. American Cancer Society [webpage on the Internet]. About Acute Myeloid Leukemia. 2017. Available from: https://www.cancer.org/ cancer/acute-myeloid-leukemia/about/key-statistics.html. Accessed February 2, 2017.

2. Shah A, Andersson TM, Rachet B, Björkholm M, Lambert PC. Survival and cure of acute myeloid leukaemia in England, 1971-2006: a population-based study. Br J Haematol. 2013;162(4):509-516.

3. Sayar H. Hypomethylating agents, another band-aid for the older AML patient? Austin J Cancer Clin Res. 2014;1(1):1002.

4. Mangan JK, Luger SM. Salvage therapy for relapsed or refractory acute myeloid leukemia. Ther Adv Hematol. 2011;2(2):73-82.

5. Roboz GJ, Rosenblat $\mathrm{T}$, Arellano $\mathrm{M}$, et al. International randomized phase III study of elacytarabine versus investigator choice in patients with relapsed/refractory acute myeloid leukemia. J Clin Oncol. 2014; 32:1919-1926.

6. Hawtin RE, Stockett DE, Byl JW, et al. Voreloxin is an anticancer quinolone derivative that intercalates DNA and poisons topoisomerase II. PLoS One. 2010;5(4):e10186.

7. Hoch U, Lynch J, Sato Y, et al. Voreloxin, formerly SNS-595, has potent activity against a broad panel of cancer cell lines and in vivo tumor models. Cancer Chemother Pharmacol. 2009;64(1):53-65.

8. Walsby EJ, Coles SJ, Knapper S, Burnett AK. The topoisomerase II inhibitor voreloxin causes cell cycle arrest and apoptosis in myeloid leukemia cells and acts in synergy with cytarabine. Haematologica. 2011; 96(3):393-399.

9. Hawtin RE, Stockett DE, Wong OK, Lundin C, Helleday T, Fox JA. Homologous recombination repair is essential for repair of vosaroxininduced DNA double-strand breaks. Oncotarget. 2010;1(7):606-619.

10. Mechetner E, Kyshtoobayeva A, Zonis S, et al. Levels of multidrug resistance (MDR1) P-glycoprotein expression by human breast cancer correlate with in vitro resistance to taxol and doxorubicin. Clin Cancer Res. 1998;4(2):389-398. 
11. Buzdar AU, Marcus C, Smith TL, Blumenschein GR. Early and delayed clinical cardiotoxicity of doxorubicin. Cancer. 1985;55(12): 2761-2765.

12. Evanchik MJ, Allen D, Yoburn JC, Silverman JA, Hoch U. Metabolism of (+)-1,4-dihydro-7-(trans-3-methoxy-4-methylamino-1-pyrrolidinyl)4-oxo-1-(2-thiaz olyl)-1,8-naphthyridine-3-carboxylic acid (voreloxin; formerly SNS-595), a novel replication-dependent DNA-damaging agent. Drug Metab Dispos. 2009;37(3):594-601.

13. Hoch U, Evanchik MJ, Silverman JA. CYP450 inhibition, induction, metabolism, and routes of elimination of SNS-595, a novel cell cycle inhibitor in phase 1 clinical trials. Presented at: 17th AACR-NCIEORTC International Conference on Molecular Targets and Cancer Therapeutics, November 14-18; 2005; Philadelphia, PA.

14. Scatena CD, Kumer JL, Arbitrario JP, et al. Voreloxin, a first-in-class anticancer quinolone derivative, acts synergistically with cytarabine in vitro and induces bone marrow aplasia in vivo. Cancer Chemother Pharmacol. 2010;66(5):881-888.

15. Lancet JE, Ravandi F, Ricklis RM, et al. A phase Ib study of vosaroxin, an anticancer quinolone derivative, in patients with relapsed or refractory acute leukemia. Leukemia. 2011;25(12):1808-1814.
16. Stuart RK, Cripe LD, Maris MB, et al. REVEAL-1, a phase 2 dose regimen optimization study of vosaroxin in older poor-risk patients with previously untreated acute myeloid leukemia. Br J Haematol. 2015; 168(6):796-805.

17. Lancet JE, Roboz GJ, Cripe LD, et al. A phase $1 \mathrm{~b} / 2$ study of combination vosaroxin and cytarabine in patients with relapsed or refractory acute myeloid leukemia. Haematologica. 2015;100(2):231-237.

18. Ravandi F, Ritchie EK, Sayar H, et al. Vosaroxin plus cytarabine versus placebo plus cytarabine in patients with first relapsed or refractory acute myeloid leukaemia (VALOR): a randomised, controlled, double-blind, multinational, phase 3 study. Lancet Oncol. 2015;16(9):1025-1036.

19. Wojtacki J, Lewicka-Nowak E, Leśniewski-Kmak K. Anthracyclineinduced cardiotoxicity: clinical course, risk factors, pathogenesis, detection and prevention - review of the literature. Med Sci Monit. 2000;6(2): 411-420.

20. Dennis M, Russell N, Hills RK, et al. Vosaroxin and vosaroxin plus low-dose Ara-C (LDAC) vs low-dose Ara-C alone in older patients with acute myeloid leukemia. Blood. 2015;125:2923-2932.

\section{Publish your work in this journal}

OncoTargets and Therapy is an international, peer-reviewed, open access journal focusing on the pathological basis of all cancers, potential targets for therapy and treatment protocols employed to improve the management of cancer patients. The journal also focuses on the impact of management programs and new therapeutic agents and protocols on

\section{Dovepress}

patient perspectives such as quality of life, adherence and satisfaction. The manuscript management system is completely online and includes a very quick and fair peer-review system, which is all easy to use. Visit http://www.dovepress.com/testimonials.php to read real quotes from published authors. 